\title{
Sliding Distance Prediction of Loess Landslide based on the Discrete Element Method
}

\author{
Yazhe Li \\ School of Geology Engineering and Geomatics \\ Chang'an University, \\ Xi'an, China \\ 809428614@qq.com
}

\author{
Wengui Tang \\ College of Geology \& Environment, \\ Xian University of Science and technology, \\ Xi'an, China \\ 450046592@qq.com
}

\begin{abstract}
The sliding distance is the most critical risk factors in landslide disasters, and many factors affects landslide sliding distance. In order to investigate the influence of various factors on the landslide sliding distance, take the loess landslides on south of Jing he River in Xi'an as the study area, make use of the discrete element simulation software PFC2D on the soil of the study area, establish a model take the five factors of the friction coefficient, the sphere particle size, slope, volume, height as the model variables, and analysis the influence of these five factors on the landslide sliding distance. By regression analysis, a number of numerical results can fit a sliding distance prediction equation of landslides, summarize the sliding distance landslide weights of various factors on the impact of the sliding distance.
\end{abstract}

Keywords-landslide; sliding distance prediction; discrete element; linear regression analysis

\section{INTRODUCTION}

Tivities arAs one of China's major geological disasters, Landslides cause heavy casualties and property losses each year. In recent decades, human ace large-scale, more and more frequent, and slope stability problems encountered are more and more prominent. In 1983, Saleshan Shan landslide, in Gansu province, slid more than $6 \mathrm{~km}$, clogged the river for 240 meters, 220 people were killed [1]. In July 2003 and March 2004, Dong Feng landslide on the south of Jing River slid twice, the length of the back to the front edge is about $360 \mathrm{~m}$ [2]. Forecasting of sliding distance for landslide disaster loss reduction is very important.

Experts and scholars have done a lot of work on the landslide movement problems, but due to the complexity of the landslide, landslide movement problems are still in the research stage of exploration. At present, experts and scholars have proposed a variety of forecasting models and methods for landslide sliding distance. Austrian scholar Schidegger [5] proposed a friction model in 1993, Chinese scholar Li Baoxiong [8], Fang Yushu [4], who have proposed a Landslide prediction formula, Wang Nian Qin [7] proposed a loess landslide sliding distance statistical prediction formula, Li Xiuzhen [4] proposed a sliding distance model for earthquake statistical forecasting.

These methods can be divided into three categories: (1) statistical forecasting model: as what Qin Wang Nian [7] and Li Xiuzhen [4] have proposed. Such methods, mainly through a number of factors, such as the geometric characteristics of landslides about macro investigation and statistics, are statistical formulas to obtain correlation between the sliding distance and its factors. Impacts on statistical forecasting model can't describe the mechanism of sliding distance (2) definitive model: sled model as Heim [9] proposed and friction model as Scheidegger [5] proposed. Definitive models are more suitable for a particular type of landslide prediction, and can't be generalized in a large range. (3)The numerical simulation model: as Jiang Xiaoyu, Qiao Jianping [10] use numerical methods to predict the landslide movement distance. Numerical methods such discrete element method is used to simulate landslide movement, in order to predict the sliding distance landslide.

PFC2D (Particle Flow Code in 2 Dimensions) is a two-dimensional discrete element method based on the numerical simulation program by setting the boundary conditions, geotechnical parameters to simulate microscopic movement characteristics of the particular rock mass. According to the strength and deformation properties of the Loess Plateau in the south of Jing River, use PFC2D to simulate the landslide on the south of Jing river. Slope model Generated by microscopic parameters of slope elevation, slope, surface friction coefficient, slip mass volume and particle size, are used to analyze the effect of the five factors on the sliding distance. Getting sliding distance landslide prediction equation of landslides on the south of Jing river and analysis the impact of various factors on the sliding distance of landslide.

\section{ESTABLISH THE PFC MODEL OF LOESS}

PFC2D based only on the Newton's laws of motion. The motion of the particles is determined by the forces acting on the particles. PFC2D offers three main soil contact description of the constitutive relations, including the contact stiffness constitutive model, Slip constitutive model and connecting constitutive model [11]. 


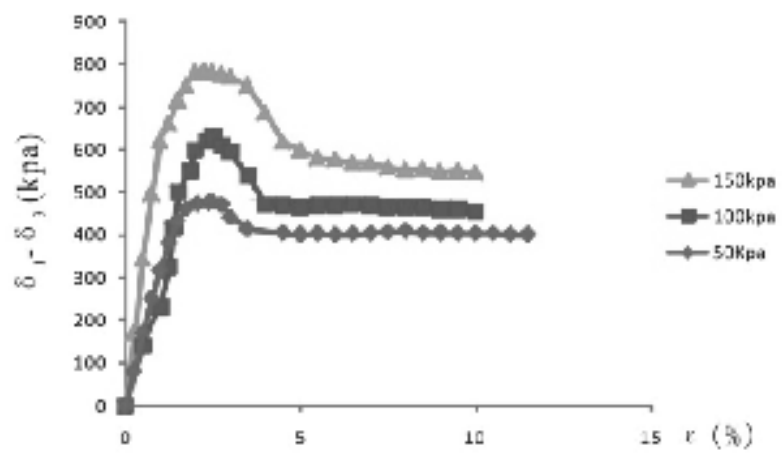

Figure.1 The stress-strain curve of undisturbed loess on the south of Jing river

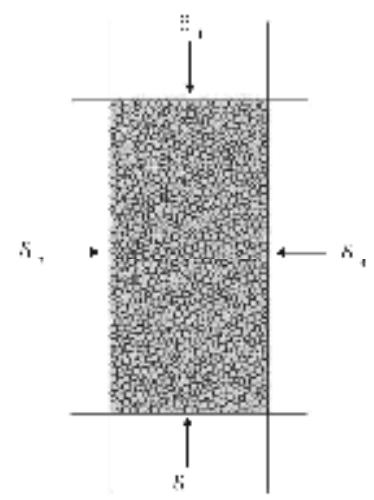

Figure.2 Schematic experimental biaxial by PFC2D

\begin{tabular}{|c|c|c|c|c|}
\hline $\begin{array}{c}\text { The particle } \\
\text { density } \\
(\mathrm{kg} / \mathrm{m3})\end{array}$ & $\begin{array}{c}\text { Particle } \\
\text { contact modulus } \\
(\mathbf{P a})\end{array}$ & $\begin{array}{l}\text { The ratio of Particle contact no- } \\
\text { rmal stiffness and shear stiffness }\end{array}$ & $\begin{array}{l}\text { Parallel link ra- } \\
\text { dius multiplier }\end{array}$ & $\begin{array}{c}\text { The ratio of normal } \\
\text { stiffness and shear stiffness of } \\
\text { Parallel link }\end{array}$ \\
\hline 1920.0 & $2.0 \mathrm{E}+07$ & 1.0 & 1.0 & 1.0 \\
\hline $\begin{array}{c}\text { The } \\
\text { particle modulus } \\
\text { of parallel link } \\
(\mathbf{P a})\end{array}$ & $\begin{array}{l}\text { particle Friction } \\
\text { coefficient }\end{array}$ & $\begin{array}{c}\text { normal strength of Parallel link } \\
\text { (Pa) }\end{array}$ & $\begin{array}{l}\text { tangential strength of } \\
\text { Parallel link (Pa) }\end{array}$ & The deviation of bond strength \\
\hline $2.0 \mathrm{E}+07$ & 1.5 & $2.0 \mathrm{E}+05$ & $2.0 \mathrm{E}+05$ & $3.0 \mathrm{E}+04$ \\
\hline
\end{tabular}

As shown in the literature 13, get the stress-strain curve of the undisturbed soil samples under different confining pressures. By the numerical servo instrument generated in PFC2D (Figure 2) numerical biaxial test, through repeated revision micro parameters to obtain the basically same stress-strain curve of triaxial test in experiment literature 10 , in order to make the model and Loess in the south of Jing river have the same dynamic characteristics. After the trial, get the particle micro parameters as shown in

\section{MODEL DESIGN}

The Loess Plateau on the south of Jing river is about $70 \mathrm{~km} 2$, the plateau form a steep slope with the Jing River floodplain terraces. Relative elevation is about $30 \sim 90 \mathrm{~m}$. And the slope is about $45^{\circ} \sim 80^{\circ}$ [3].

That slip mass volume and topography are the key factors affecting the sliding distance has been widely recognized by scholars[4-10]. According to characteristics of the loess plateau on the south of Jing river, establish a model to consider the affect of friction coefficient, the particle size, slope , height difference and slippery body size, as shown in Figure 3.

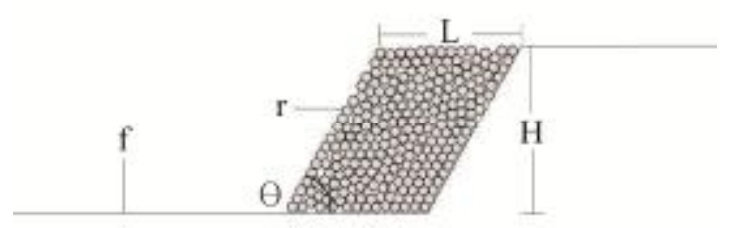

Figure.3 Schematic numerical model

$\mathrm{f}$ is the ground friction coefficient; $\mathrm{r}$ is the radius of the particle size; $\theta$ is the slope; $\mathrm{V}=\mathrm{L} * \mathrm{H}$ is the slippery body size; $\mathrm{H}$ is the height difference; $\mathrm{d}$ sliding distance landslide.

According to PFC 2D powerful customization features, the calibration process established particle microscopic parameters of loess landslides on the south of Jing river.

\begin{tabular}{|c|c|c|c|c|c|}
\hline parameter & $\boldsymbol{f}$ & $\boldsymbol{r ( m )}$ & $\boldsymbol{\theta}\left(\boldsymbol{(}^{\mathbf{0}}\right)$ & $\boldsymbol{V}=\boldsymbol{L}^{*} \boldsymbol{H}\left(\mathbf{m}^{\mathbf{3}}\right)$ & $\boldsymbol{H}(\mathbf{m})$ \\
\hline The range of the parameter & $0.03-0.99$ & $0.24-0.89$ & $20-80$ & $125-3117$ & $9-90$ \\
\hline
\end{tabular}




\section{ANALYSIS OF THE FACTORS THAT} INFLUENCE LANDSLIDE SLIDING DISTANCE

\section{A. The friction coefficient of sliding distance on the loess landslide influence}

Change the model coefficient of friction, sliding distance and friction coefficient obtained trend line shown in Figure 4. Affect of the friction coefficient on the sliding distance is divided into three phases: In the first stage, the coefficient of friction is greater than 0.4 , the model does not slip or slide within $5 \mathrm{~m}$; when the friction coefficient is less than 0.2 , as the friction coefficient decreases, a significant increase shows in sliding distance; a transition phase is in the middle. the relationship of the ground friction coefficient of the sliding distance can be determined:

$$
D=-31.1 \ln (f)-19.24 \quad(1)
$$

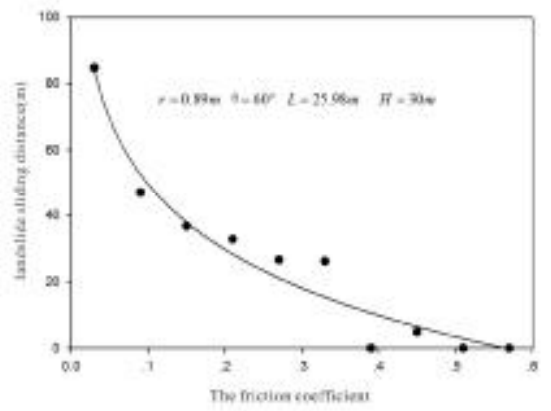

Figure 4 The curve of landslide sliding distance versus ground friction coefficient

\section{B. Influence of particle radius on the sliding distance}

Change the particle radius, the impact on landslide sliding distance can be seen. With the landslide particle radius gets smaller, sliding distance increased slowly. We can speculate that The slip mass crushed, particle radius gets smaller, showing the nature of fluid, the energy of slip mass slip translate more into growth sliding distance.

Get the trend line equation of radius particles versus sliding distance:

$$
D=-7.338 r+42.39
$$

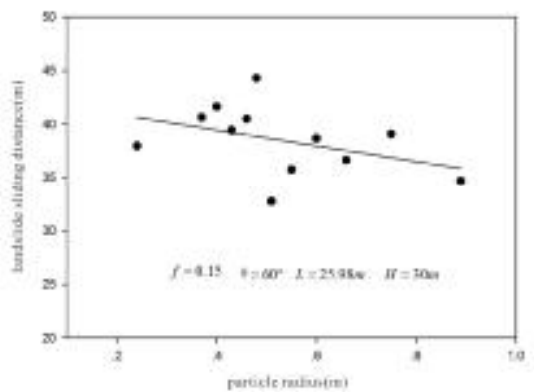

Figure 5 The curve of landslide sliding distance versus particle diameter

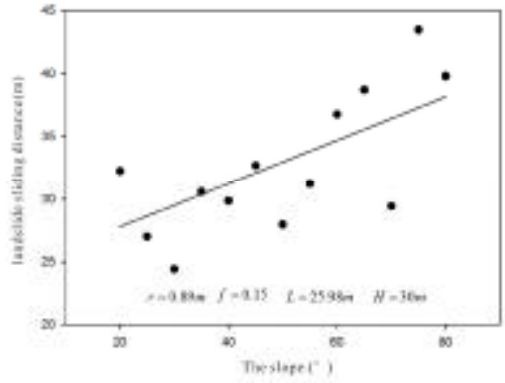

6 The curve of landslide sliding distance versus slope

Figure

\section{Influence of slope on the sliding distance}

Changing the slope, at intervals of $5^{\circ}$, analyze the impact of the landslide slope on sliding distance. As can be seen from the curve of slope versus sliding distance, when the slope is increased, there is an increasing trend away from the slide.

\section{Influence of slip mass volume on the sliding distance}

Change slip mass volume $\mathrm{V}(\mathrm{L} * \mathrm{H})$ in the range of $125 \mathrm{~m} 3-3117 \mathrm{~m} 3$, When the distance between crack the leading edge is less than $25 \mathrm{~m}$, there will be a significant increase as the slip mass volume increases; when the crack is located at a distance away from the front edge, as the volume of slip mass increase, landslide sliding distance remain at a level, indicating that at this time the crack has not become a sliding surface, would not achieve the control action. Get the trend line equation:

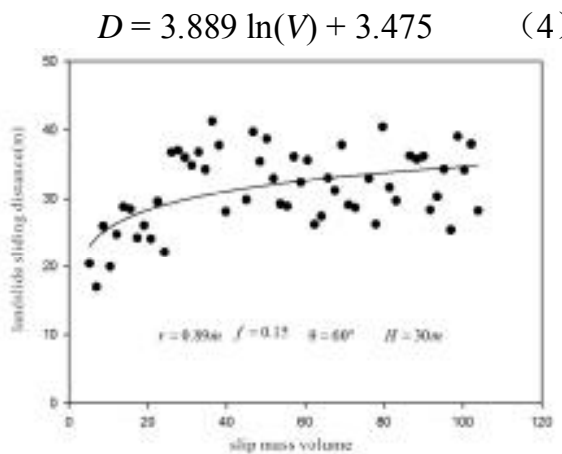

Figure 7 The curve of landslide sliding distance versus

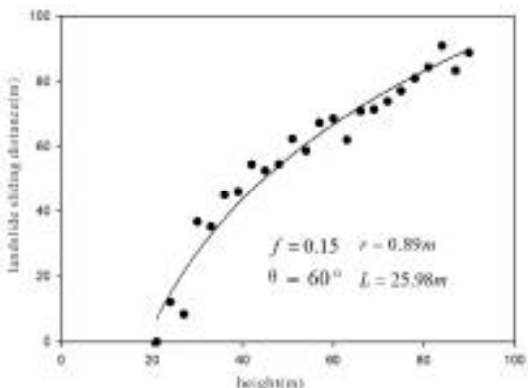

Figure 8 The curve of landslide sliding distance versus height

\section{E. Influence of elevation on the sliding distance}

Elevation rang from $9 \mathrm{~m}$ to $90 \mathrm{~m}$, analysis of the influence of elevation on the sliding distance. Effect of elevation on the loess landslides sliding distance found take on a logarithmic relationship. When the height is less than a certain value, slope is stable and slip will not occurs. Therefore, to determine the height of slope though numerical methods has a high significance for field 
excavation slope. get the trend line equation:

$$
D=54.92 \ln (H)-158
$$

\section{REGRESSION ANALYSIS OF FACTORS AFFECT SLIDING DISTANCE}

\section{A. fit regression equation}

By analyzing the various factors on the influence of the sliding distance, we found each factor had a relationship with the sliding distance. Ground friction coefficient, height have the closest relationship with sliding distance. By changing the value of factors in numerical experiments, obtain multiple sets of experimental data, take the equation (1) to (5) into consideration, do multiple linear regression analysis, get the regression equation:

$$
\begin{gathered}
D=-17.109 \ln (f)-16.102 r+21.786 \mathrm{e}^{0.006 \theta}+1.556 \ln (V) \\
+24.55 \ln (H)-111.391(6)
\end{gathered}
$$

As reference equations of loess landslides to predict sliding distance, when $D$ is negative, that slope is considered stable, sliding does not occur. Multiple correlation coefficient equation is 0.632 , indicating that the equation has been able to fit the role of numerical results.

\section{B. Analysis of the various factors}

Analyze the impact of various factors on landslide sliding distance by stepwise regression, the greater the absolute value of standardized regression coefficients, the greater that factor affects landslide sliding distance. Regression coefficients of friction coefficient, height, particle radius, slope, slip mass were $-0.753,0.349$, $0.158,0.138,0.043$, indicating that the impact of various factors on the landslide sliding distance from large to small are the friction coefficient, height, particle radius, slope, volume.

\section{CONCLUSION}

Based on the discrete element numerical simulation to study the Influence of friction coefficient, particle size, slope, slip mass size and height five on the loess landslide sliding distance, obtain the influence law for each factor on sliding distance. Get the relationship of Loess landslide sliding distance friction coefficient, the sphere radius of the particles, slip mass size, slope, distance of the crack with the leading edge $: D=C_{1} \ln (f)-C_{2}, D=\mathrm{C}_{3} \mathrm{r}+C_{4}, D=$
$C_{5} \mathrm{e}^{0.006 \theta}, D=C_{6} \ln (V)+C_{7}, D=C_{8} \ln (H)-\mathrm{C}_{9}(C *$ is a constant).

Through a large number of numerical experiments and multivariate regression analysis, obtain a comprehensive loess landslides prediction equation which take five factors into consideration.

In the regression analysis, the partial regressions coefficient of friction, height, particle radius, slope, slip mass were $-0.753,0.349,-0.158,0.138,0.043$, the impact of various factors on the landslide sliding distance from large to a small friction coefficient, respectively, height, particle radius, slope, volume.

\section{REFERENCES}

[1] Lv Hongtu, Yang Shuangqing, Ai Nanshan. Relationship discussion of Saleshan landslide and new tectonic stress field $[\mathrm{J}]$ Lanzhou University, 1984,04: 96-104.

[2] Liao Hongjian, Li Tao, Peng Jianbing. strength characteristics study of high and steep slope loess landslide [J]. Rock and Soil Mechanics, 2011,07: 1939-1944.

[3] Lei Xiangyi. The hazards of loess landslides in the southern tableland of Jingyang county, Shaanxi and their relationship with the channel water into fields[J]. Journal of Engineering Geology, 1994, 3(1): 56-64.

[4] li Xiu-zhen, Kong Ji-ming. Runout Distance Estimation of Landslides Triggered by " $5 \cdot 12$ ” Wenchuan Earthquake[J]. Journal of Engineering Geology,2010.9:243-249.

[5] Adrian E Scheidegger. On the prediction of the reach and velocity of catastrophic landslide $[\mathrm{J}]$. Rock Mechanics, 1973, 5: $231-236$.

[6] Fang Yushu.Studies of predict large-scale high-speed landslide. [A]. 1991:11.

[7] Wang Nianqin, Zhang Zhuoyuan, Wang Jiading. A forecasting method of sliding distance on typical loess landslides[J]. Journal of Northwest University: Natural Science Edition, 2003, 33( 1) $111-114$.

[8] Li Baoxiong, Wang Dekai. A new theory of space forecastfor loess landslides[J]. Journal of Gansu Science, 1998, 10( 3) : 57 -58 .

[9] Hungr O. A model for the runout analysis of rapid flow slides, debris flows, and Avalanches $[\mathrm{J}]$. Canadian Geotechnical Journal, 1995, 32:610 - 623.

[10] Jiang Xiaoyu, Qiao Jianping. Contact mechanics model for risk predication of typical landslides[J]. Engineering Melhanics, $2006,23(8): 106-109$.

[11] Itasca Consulting Group, Inc. PFC2D (partial flow code in 3 dimension) version 3.0[R]. Minneapolis, Minnesota: Itasca Consulting Group, Inc., 2003.

[12] Duan Zhao . Study on the Trigger Mechanism of Loess Landslide - A Case Study of the Loess Landslide in the South Bank of Lower Jing River[D]

[13] Shreve, R.L. The Blackhawk landslide. Special Paper, Geological Society of America Bulletin, 1968, vol. 108. 47 pp. 